\title{
The Impact of Lean Transformation on the Organizational Performance: The Case of Public Utilities in Greece
}

\author{
Michail K. Angelopoulos, Yannis A. Pollalis \\ Department of Economics, University of Piraeus, Piraeus, Greece \\ Email: mangelopoulos66@gmail.com
}

How to cite this paper: Angelopoulos, M.K. and Pollalis, Y.A. (2021) The Impact of Lean Transformation on the Organizational Performance: The Case of Public Utilities in Greece. Open Journal of Applied Sciences, 11, 684-698.

https://doi.org/10.4236/ojapps.2021.116050

Received: May 5, 2021

Accepted: June 22, 2021

Published: June 25, 2021

Copyright (c) 2021 by author(s) and Scientific Research Publishing Inc. This work is licensed under the Creative Commons Attribution International License (CC BY 4.0).

http://creativecommons.org/licenses/by/4.0/

\begin{abstract}
Purpose: Lean Management concerns a strategy or philosophy aiming at saving resource practices and curtailment of public expenses, with ultimate objective of the enhancement of the organizational performance. By extension, the successful integration of the Lean Management leads to positive organizational results, such as higher quality, along with improved financial, environmental and business market performance. Although a lot of studies related to the effect of Lean production on the organizational performance have been conducted, empirical findings that examine the case of the public sector are absent. Additionally, there is no precise mechanism through which the Lean Management determines the organizational performance of the public utility companies. The above mentioned research gap is examined with this research, given that it investigates the influence of the Successful Lean Management on the Organizational Performance (Environmental Performance, Financial Performance, Business Performance) in public utilities in Greece. Research Methodology: The research method combines bibliographic research and empirical - with quantitative method-through a case study. More specifically, via quantitative approach, which was based on sample research with standardized questionnaire, performed in two of the biggest and most important public utilities in Greece, the Public Power Corporation S.A. (PPC S.A.) and the Athens Water Supply and Sewerage Company (EYDAP S.A). Findings: Quantitative findings from this illustrated that the successful transformation towards the Lean principles/saving resources affects positively the Business Market Performance, the Environmental and the Financial Performance. Limitations: Main restrictions of the current study are the capitalization of random sample and the strict focus on Greek public utilities that function under conditions of competition. Consequently, whichever generalizations for the whole Public Sector as well as for businesses of the private
\end{abstract}


sector it would be better to be avoided, as they differ concerning their structural and functional features and their organizational culture.

\section{Keywords}

Lean Management, Organizational Performance, Public Management

\section{Introduction}

Lean Management concerns a strategy or philosophy aiming at saving resource prac-tices and curtailment of public expenses, which can lead to positive organizational results, such as higher quality, along with improved financial, environmental and business market performance [1] [2] [3] [4].

In the Greek public sector the transition to the saving resources principles and the Lean Management started taking place more intensely at the end of 2014, when the incorporation of transparency and open data principles began, in public companies [5]. Despite the fact that the last few years some positive steps were made, mainly due to the new technological advances, the Greek public companies still continue to be characterized by bureaucracy and by deficiency in complete strategic action and utilization of the disposable public assets in the best way possible [6].

More analytically, the transition of the Greek Sector towards the Lean Management seems to be encouraged by the greek laws and the implementation of the national and business plan actions, supported by national and European funds. Particularly in the Business Programs many specialized actions are integrated that strive for solutions to serious issues of the Greek Management, such as the "Introduction of New Management Methods", the "Quality of Customer Service", the "Upgrade of Human Workforce" and the "Introduction of Information Technology (IT) in the Public Sector".

In this context were materialized and continue to be implemented Programs such as for example, the "Quality for the Citizen", the "TAXIS application", the Organizational Programs "State" of the ministry of the Interior and Administrative Reconstruction, the "Society of Information" the "Union", the Business Program "Human Workforce Development, Training and Lifelong Education" 2014-2020, the diavgeia.gov, the program of digitalization and codification of the legislation "e-themis", digital signatures, the creation of data.gov.gr that supplies us with open public data.

The above mentioned programs contribute to the direction of Lean Management since they aim at the reduction of bureaucracy, the simplification of the procedures, the encouragement of transparency, the homogenization of the actions, the capitalization of ITC (Information Technology Communications), the introduction of the term of total quality and the progressive introduction of measuring efficiency variables and the evaluation of employees and services having 
as criterion the efficiency.

The attempts for implementation, in the Public sector and especially in the public companies, of contemporary forms of management that are consistent with the Lean approach, such as the Management with set targets, the Total Quality Management, the assessment of the provided public services, are highly promising but at primary stages. More specifically, the introduction of serious initiatives for the restructuring of the Public sector in Greece concerns only the last two decades, having as first step the function of Citizens' Service Centre (CSC), contrary to other European countries and the United States of America that are engaged since the 1950 .

In any case, there is the ability for amelioration of the provided services from the public companies with the objective of a better and faster customer-citizen service, by offering better working conditions and improving their efficiency and productivity [7]. This can become true without negatively affecting the restructure, the financial reinforcement of the country from abroad or the new investments in technological infrastructures and information systems with the implementation of the Lean Management practices to the services of the public companies/organizations [8].

According to the systematic literature review of Arlbjørn et al. [9] there are few studies examining the implementation of Lean Management in public organization as well as to utility companies in general. Consequently, there is a growing demand as far as it concerns conducting reliable research that would examine the smooth implementation and the impacts of the Lean Management principles on the public sector [10]. Simultaneously, there is absence of findings that examine the precise influence of Lean Management on various efficiency variables of the Organizational Performance (the Financial Performance, the Environmental Performance and the Business Market Performance) in public organizations.

It has been proven that the success concerning the realization of the saving resources tasks depends to a great extent from the opinions of the people evaluating them. The Financial Performance concerns the costs (functional, working etc.) and the income of the public utility company, while the non-Financial Performance is related with the fulfillment of the organizational targets, the amelioration of delivery time of the products and the prompt service of the customers [11].

Most of the times, the project managers determine the success rate through the completion of the project according to the planned budget and the time horizon [11]. The users of the saving resources system usually decide on the success of the project through their smooth interaction with it.

In turn, the top managers believe that such a system is correctly implemented when the business accomplishes the reinforcement of the Organizational Performance and complete accomplishment of the already set targets [11] [12] [13].

According to Al-Mashari et al. [14], the main objective of a dwindling ex- 
penses system is the fortification of the organizational performances, by incorporating a range of business procedures in every functional department of the business. This integration enables the best organization of the information flow, in the business as well as among its customers and suppliers [11] [14].

Corresponding research of Hwang and Min [15] proved that the effective implementation of the saving resources system is positively with and to a statistically important level with the organizational capability (e.g. information access, business processes improvement, products innovation etc.) and the Organizational Performance of the business. Botta-Genoulaz et al. [16] also supported that the successful materialization of the tasks for the reduction of the expenses positively influence the performance of a company.

Additionally, comparing businesses of various fields, observed that the ones that utilized in an efficient way the aforementioned systems noticed an increase in their Organizational Performance, compared with those that did not possess them. More analytically, they mentioned that the turnover of the companies that had actualized successful saving resources works had significantly improved. Though, they noticed that the outcome varied depending on the businesses size [17] [18] [19], in turn, proved the existence of a positive and statistically important relation between the successful implementation of the saving expenses works and the Organizational Performance.

\section{Research Question \& Research Methodology}

The research question of this study is the examination of the integration influence of the Lean Management Principles (Lean Transformation) on the Organizational Performance of Public Utilities in Greece.

It is a fact that there are not enough studies conducted in Greece that deal with lean Management in public utilities and how this may affect them. This research gap motivated us to study and answer the question about how Lean Management affect important factors that determine the viability and organizational performance of public utilities in Greece

In this paper, we used as research tool the empirical-with quantitative method-re-search through case study. More specifically, via quantitative approach, which was based on sample research with standardized questionnaire, performed in two of the biggest and most important public companies in Greece, the Public Power Corporation S.A. (PPC S.A.) and the Athens Water Supply and Sewerage Company (EYDAP S.A), the research question was looked into.

The quantitative approach is based on sample research with standardized questionnaire, offering the ability to approach a satisfactory proportion of the population for the investigation of theories and inquiries [20].

The questionnaire constitutes the most fundamental tool concerning the data collection in a quantitative research. Planning and conducting this questionnaire, for the specific study, was actualized oriented to the materialization of the goals of the research at the two biggest Greek enterprises of public interest and 
utility purpose: PPC S.A. and EYDAP S.A. It was based on multiple rules, in order for the questions not to be biased and lead to erroneous outcome [21].

In order for the respondents to remain impartial, there was appropriate combination and composition of questions along with the capitalization of appropriate scales. More specifically, the questions were mixed, so that the participants would find challenging to set apart the individual and the dependent variable of the research. Convenience sample was utilized, which is characterized by low cost and time of realization, while when performed properly it can reduce the chance of a statistic error [21]. This is a method of no-odds where the subjects of the research are chosen based on their proximity and easy accessibility [22] and it is the most popular when concerning workforce since it is feasible to include the vast majority of the population. Simultaneously, the method of snowball sampling was utilized, during which it was asked from the participants to forward the questionnaire to their colleagues working in the same sector. To be more exact, the procedure of sampling used in the current research is the following.

\subsection{Population}

The employees in public companies (PPC S.A., EYDAP S.A) occupied in Directorates and Sectors such as: IT, operations, energy, management, strategic planning, research, human resource management, marketing and procurement.

\subsection{Sample Size}

From the 480 questionnaires being handed out, 343 valid answers were collected. Consequently, the response rate was $71.5 \%$.

\subsection{Realization of Sampling Plan and Collection of Data}

Sampling was performed in the aforementioned Directorates and Sectors from January 2019 till September 2019 (Figure 1). The research was being conducted in

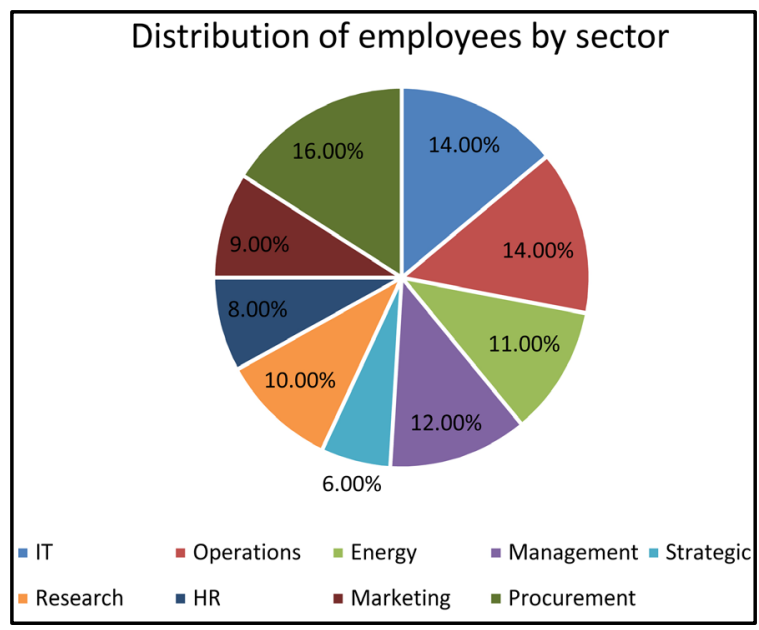

Figure 1. Distribution of employees by sector. 
the morning and at noon, so as to ensure a satisfactory representation of the sample. The delivery of the questionnaire was performed both traditionally (hand by hand) and online. The online distribution of the questionnaire was made according to the lists of the e-mails given to the human resources Directorate of each company. At this point it worth's mentioning that we took advantage of snowball sampling, as it was asked from the participants to hand out the questionnaire to their colleagues (Figure 2).

\subsection{Procedure of Codification and Insert of Data}

The variables of the research (dependent variables CSFs, independent variable Lean Transformation) include various scales, such as the Likert scale. The possible alternatives were coded using relevant numbers and headlines with the assistance of "Microsoft Excel" spreadsheet. Moreover, the data from the participants' responses were inserted on a data basis "SPSS Version 23 for Windows", always in accordance with the previously mentioned codification. Finally, the data were analyzed with the aid of the specific statistic package and the "IBM SPSS Amos 21".

The theoretical model of the research is being presented in the following Figure 3:

The research question will be investigated with the assistance of 3 research hypotheses.

By deduction, the following research hypothesis can be conveyed:

H1: The Successful Integration of the Lean Management principles/systems positively affects the Business Market Performance of a Public Utility Company.

H2: The Successful Integration of the Lean Management principles/systems has a favorable effect on the Environmental Performance of a Public Utility Company.

H3: The Successful Integration of the Lean Management principles/systems has a positive influence on the Financial Performance of Public Utility Company.

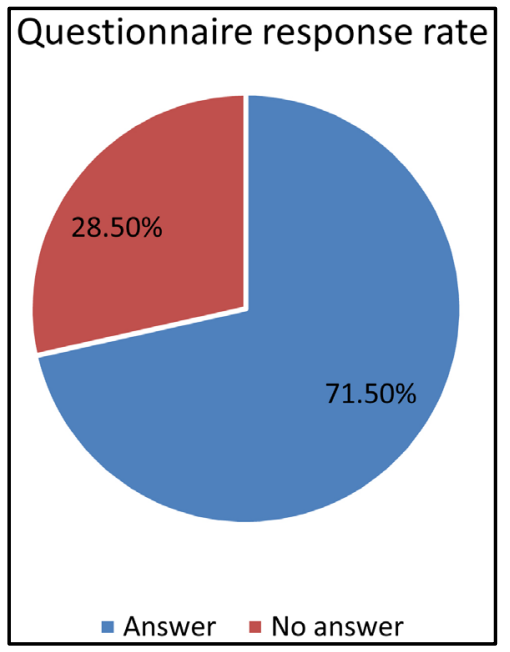

Figure 2. Queationnaire response rate. 


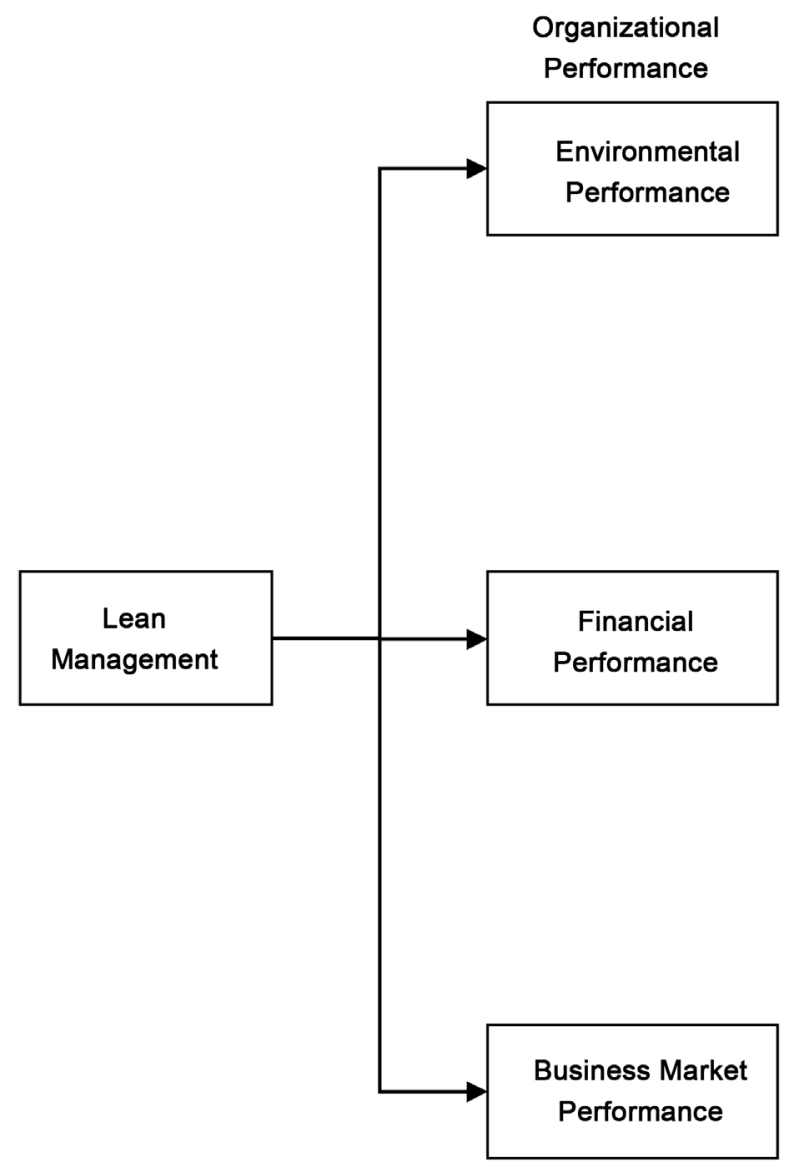

Figure 3. The theoretical model of research.

\section{Findings}

To check the validity of the research tool, an Exploratory Factor Analysis (EFA) was initially performed. This analysis aims to investigate the composition of the scales used and to create fewer variables compared to the original questionnaire. The latter is achieved through the grouping of proposals (items) located within the same factor. Thus, propositions that belong to the same scale have a high interrelationship and vice versa. Consequently, each set of sentences is calculated as a single factor using the average of the answers given by the respondents. At this point it should be emphasized that with Exploratory Factor Analysis, the construction of structures that affect a set of variables is examined. The following equation is the factor analysis equation, which states a linear type relational relation:

$$
\begin{aligned}
& X_{1}-\mu_{1}=I_{11} F_{1}+I_{12} F_{2}+\cdots+I_{1 m} F_{m}+e_{1} \\
& X_{2}-\mu_{2}=I_{21} F_{1}+I_{22} F_{2}+\cdots+I_{2 m} F_{m}+e_{2} \\
& X_{n}-\mu_{n}=I_{n 1} F_{1}+I_{n 2} F_{2}+\cdots+I_{n m} F_{m}+e_{n}
\end{aligned}
$$

$F_{m}$ denotes the generalized variables and $I_{n m}$ their coefficients. The symbol en refers to the random error of the interpretive variable $X_{n}$ and is related exclusively to it. The simplest form of factor analysis equation is: 


$$
(X-\mu)_{n \times 1}=I_{n \times m} F_{n \times m}+e_{n \times 1}
$$

The rotation method used in Factor Analysis was Varimax and acceptable charge levels were those above 0.50 . From the statistical point of view, this method used to simplify a factor depending on the most important propositions that characterize it. More specifically, Varimax maximizes the sum of the squared variations (squared correlations between propositions/variables and factors) of each proposition to create single factors. The following equation expresses the data exchange criterion of the Varimax method:

$$
R_{\text {VARIMAX }}=\arg \max _{R}\left(\frac{1}{p} \sum_{j=1}^{k} \sum_{i=1}^{p}(\Lambda R)_{i j}^{4}-\sum_{j=1}^{k}\left(\frac{1}{p} \sum_{i=1}^{p}(\Lambda R)_{i j}^{2}\right)^{2}\right)
$$

The reliability of the single factors/scales was calculated based on the Cronbach's Alpha index. Also, the possibility of increasing the value of this index in case of removal of certain proposals/statements ("scale if item deleted") was investigated. Cronbach Alpha values equal to or greater than 0.70 are considered acceptable. Consequently, scales with a Cronbach Alpha index (a) that reach up to 0.80 are considered quite satisfactory for the composition and validity of the factors, while up to 0.90 (or in rare cases above 0.90) are characterized as extremely reliable. In the case of the present dissertation, the reliability index was in all cases greater than 0.70 , proving the existence of a satisfactory level of internal consistency.

In general, Factor Analysis showed that each group of propositions is a separate factor with loadings over 0.50 . Loads are the weight of each variable/proposition in each factor (i.e. it presents the internal correlation index of each proposition in a single factor). The higher the charge, the easier it is to interpret the factor. In general, through factor analysis, information is provided that verifies the existence of convergent validity.

In addition, most of the proposals were not identified in two separate factors, while in all cases where this was found, the "problematic" proposal that showed cross-loading was excluded from the analysis. In other words, propositions charged to two different factors were excluded from factor analysis. Therefore, there is satisfactory discriminant validity.

Applying the Cook's Distance method the collected data from the respondents' replies were checked for high residuals and for bias as far as it concerns the participants' answers. The method is used in various ways:

Indicate points that affect data and that are worth checking for validity.

Indicate areas where they could be used in the design to obtain more (points) data.

$$
D_{i}=\frac{\sum_{j=1}^{n}\left(\hat{y}_{j}-\hat{y}_{j(i)}\right)^{2}}{p s^{2}}
$$

Observation $i(i=1,2, \cdots, n)$ is the sum of all changes in a regression model when observation $i$ is subtracted. 
where $\hat{y}_{j(i)}$ is a customized response value obtained when excluding observation $i$ and

where $s^{2}=\frac{e^{\mathrm{T}} e}{n-p}$

It is the mean squared error for regression model.

In the current study, no answer was omitted as outliers or unsatisfying rates did not appear since the Cook's Distance indicator in every case was below 1 . Since a sample of convenience was used for the current research, which means non-random sampling was performed, a non-normal distribution is being noticed, as expected.

From the Organizational Performance questionnaire 3 single factors/scales occurred.

The first factor concerns the Business Market Performance and it consists of 4 statements (with coding, Business 1, Business 2, Business 3, Business 4) from which, one was negatively verbalized ( statement 1 of the 6th question, with the name Business 1) so reverse coding was performed. The Cronbach's Alpha indicator of the specific scale is 0.75 that declares complete credibility. To analyze it further, the procedure performed was as follows:

- Price 5 became 1 .

- Price 4 became 2 .

- Price 3 remained 3 .

- Price 2 became 4 .

- Price 1 became 5 .

Cronbanch's Alpha Index (a) is an indicator of internal consistency, that is, how closely a set of elements is related as a group. It is considered to be a measure of reliability. From a technical point of view, (a) is not a statistical test-it is a factor of reliability and coherence. The general rule is when $\alpha>0.70$ is good, if $\alpha>0.80$ is better and when $\alpha>0.90$ is even better the internal consistency of the sample of data. The index can be written as a function of a number of items in a test and an average correlation between the items.

$$
\alpha=\frac{N \bar{c}}{\bar{u}+(N-1) \bar{c}}
$$

$N$ : number of items;

$\bar{c}$ : Average variability between data;

$\bar{u}:$ Mean variation.

After the above procedure the factor analysis was performed again with the new reversed suggestion. Consequently, the "negative" meaning of the suggestion was changed and it acquired "positive" meaning, like the rest of the statements of this specific scale.

Table 1 that follows presents the loadings of each statement and the credibility of the "Business Market Performance" scale.

The second factor refers to the Environmental Performance, which consists 
Table 1. Business market performance scale.

\begin{tabular}{lc}
\hline \multicolumn{1}{c}{ Statements } & Loadings \\
\hline $\begin{array}{l}\text { 1) Based on the current situation, I believe that the competitors of the } \\
\text { public utility company have detracted and continue to detract market } \\
\text { shares from the company I work for (Business 1). }\end{array}$ & 0.62 \\
2) The image the customers of the specific business possess is more positive \\
from that of their competitors (Business 2).
\end{tabular}

* No substantial reinforcement of the credibility indicator was noticed in case a statement was erased.

of 3 codified statements under the name Environmental 1, Environmental 2, Environmental 3. This specific scale is very reliable since it presented Cronbach's Alpha indicator equal 0.85 .

Table 2 that follows depicts the loadings of each statement and the reliability of the "Environmental Performance" scale.

The third factor is the Financial Performance which consists of 3 statements codified as Financial 1, Financial 2 and Financial 3. This specific scale is highly credible since it presented Cronbach's Alpha indicator equal to 0.79 .

Based on the above the Table 3 has been formed.

With ultimate target the control of $\mathrm{H} 1-\mathrm{H} 3$ research hypotheses, an association analysis was performed through "Pearson" statistic control. This specific analysis aims at the intension measurement of the linear link between two variables. The following equation presents the statistic control "Pearson" [23]:

$$
\rho_{x y}=\frac{\operatorname{Cov}(x, y)}{\sigma_{x} \sigma_{y}}
$$

where,

$\rho_{x y}$ is Pearson $(r)$ link indicator,

$\operatorname{Cov}(x, y)$ is the covariance of $x$ and $y$ variables;

$\sigma_{x}$ is the standard deviation of $x$ variable;

$\sigma_{y}$ is the standard deviation of $y$ variable.

As long as the prices of the association coefficient $(r)$ tend towards \pm 1 , the association degree of the variables will be even more perfect. Conversely, as long as $r$ tends towards 0 the said association becomes weaker. For the characterization of every influence the following limits can be applied [23]:

- If $r>0.7$, strong influence.

- If $r \leq 0.6$, medium to strong influence.

- If $r \leq 0.4$, medium influence.

- If $r \leq 0.3$, weak influence. 
Table 2. Scale environmental performance.

\begin{tabular}{lc}
\hline \multicolumn{1}{c}{ Statements } & Loadings \\
\hline $\begin{array}{l}\text { 5) Thanks to the capitalization of the resource saving systems and } \\
\text { procedures, the public utility company I am employed at, has reduced } \\
\text { waste (e.g. energy) (Environmental 1). }\end{array}$ & 0.91 \\
6) Because of the integration of the specific systems and procedures, the \\
public utility company used more efficiently the renewable sources of \\
energy and generally its business resources (Environmental 2). \\
$\begin{array}{l}\text { 7) Through the implementation of resource saving systems and processes, } \\
\text { the particular public utility company has reduced the possibility, serious } \\
\text { accidents against the natural environment (Environmental 3). }\end{array}$ \\
$\begin{array}{l}\text { Cronbach's Alpha Indicator* } \\
\text { C. }\end{array}$
\end{tabular}

*No substantial fortification of the credibility indicator was noticed in case a statement was erased.

Table 3. Scale financial performance.

\begin{tabular}{lc}
\hline \multicolumn{1}{c}{ Statements } & Loadings \\
\hline $\begin{array}{l}\text { 9) As far as it concerns the efficiency of the capitals, the efficiency levels of } \\
\text { the investment (Return On Investment, ROI), have improved the last 4 } \\
\text { years (Financial 1). }\end{array}$ & 0.85 \\
10) Generally, the public utility company where I am employed shows \\
better financial performance in comparison with the competition (Financial \\
2). \\
$\begin{array}{l}\text { 11) In a 4 year time a productivity boost in the business has been observed } \\
\text { (e.g. reduction of the functional cost, labor cost etc.) (Financial 3). } \\
\text { Cronbach's Alpha Indicator* }\end{array}$ \\
\hline
\end{tabular}

* Substantial reinforcement of the credibility indicator was proven, in case statement 8 was erased, that is why it was exempted.

More in depth, the aforementioned analysis was performed among the scales "Business Market Performance", "Environmental Performance", "Financial Performance" and "Lean Transformation". From the association analysis arose that the Successful Integration of the Lean Management Principles positively affects from medium to high degree $(r=0.56, p=0.00<0.01)$ the Business Market Performance. Moreover, it was proven that the Lean Transformation is related positively, to a statistically important and strong degree $(r=0.71, p=0.00<$ $0.01)$ with the Environmental Performance. At the same time it was noticed that the Successful Integration of the Lean Management Principles/sys-tems affects positively and powerfully $(r=0.65, p=0.00<0.01)$ the Financial Performance. Consequently, the H1, H2, H3 hypotheses were verified. For more information related to the results of Pearson association analysis, are displayed on Table 4.

Table 5 that follows presents as a whole the results of the suggested research hypotheses. 
Table 4. The Association of lean transformation with organizational performance factors.

\begin{tabular}{ccccc}
\hline & & $\begin{array}{c}\text { Business Market } \\
\text { Performance }\end{array}$ & $\begin{array}{c}\text { Environmental } \\
\text { Performance }\end{array}$ & $\begin{array}{c}\text { Financial } \\
\text { Performance }\end{array}$ \\
\hline & $\begin{array}{c}\text { Pearson } \\
\text { Correlation }\end{array}$ & $\mathbf{0 . 5 6}$ & $\mathbf{0 . 7 1}$ & $\mathbf{0 . 6 5}$ \\
$\begin{array}{c}\text { Lean } \\
\text { Transformation }\end{array}$ & Sig. (2-tailed) & 0.00 & 0.00 & 0.00 \\
& $\mathrm{~N}$ & 343 & 343 & 343 \\
\hline
\end{tabular}

${ }^{*}$ Correlation is significant at the 0.01 level (2-tailed).

Table 5. Results of research hypotheses.

\begin{tabular}{clll}
\hline Hypothesis & \multicolumn{1}{c}{ Description } & $\begin{array}{c}\text { Statistic } \\
\text { importance } \\
\text { (p-value) }\end{array}$ & Result \\
\hline H1 & $\begin{array}{l}\text { The Successful Integration of the Lean } \\
\text { Management principles/systems positively } \\
\text { affects the Business Market Performance. }\end{array}$ & $0.00<0.01$ & Confirmed \\
& $\begin{array}{l}\text { The Successful Integration of the Lean } \\
\text { Management principles/systems positively } \\
\text { influences the Environmental Performance } \\
\text { of a Public Utility Company }\end{array}$ & $0.00<0.01$ & Confirmed \\
& $\begin{array}{l}\text { The Successful Integration of the Lean } \\
\text { Management principles/systems positively } \\
\text { affects the Financial Performance of a }\end{array}$ & $0.00<0.01$ & Confirmed \\
& Public Utility Company. & & \\
\hline
\end{tabular}

\section{Conclusions}

The findings have shown that the Successful Lean Management is positively and strongly related to the Business Market Performance, the Financial Performance and the Environmental Performance.

More in depth, through the effective saving resources a company can detract greater market share percentages, to present a more positive company image and strengthen its customers' credibility. Additionally, it is capable to reduce its expenses, to utilize more efficiently the energy sources and minimize the possibility of serious accidents against the natural environment, occurring. Through the effective implementation of Lean Management it was verified that a public utility company demonstrates higher financial performance, by enhancing its productivity.

The above-mentioned findings align with literature where it is proved that the successful integration of the resources saving systems boosts the Financial and Environmental Performance of the public utility company, as well as its Business Market Performance.

Moreover, we confirmed, the presence of effective Lean Management fortifies the Organizational Performance of the public utility company by enhancing the levels of service and maintenance of the customers, the managerial decision making, the productivity, the relationships between the suppliers and the sales of the 
already existing products.

Finally, we verified, who observed that there is a positive and statistically important link between the successful implementation of the resource saving works and the Organizational Performance.

\section{Suggestions for Future Research}

The current study can constitute the basis when conducting additional future research which will enrich and develop the findings already discovered. To analyze it further, the investigation of the influence the digital transformation can bring about is suggested, along with the bureaucracy on the successful integration of Lean Management in the public utilities organizations/companies.

Furthermore, it is recommended to take advantage of secondary data of the private and the public sector, which have materialized Lean Management works at a successful and unsuccessful level, so as to make comparisons then. Also, the points of view of the customers-citizens can be applied for further amelioration of the public services, so as to be incorporated into the Lean Transformation process.

\section{Conflicts of Interest}

The authors declare no conflicts of interest regarding the publication of this paper.

\section{References}

[1] Womack, J.P., Jones, D.T. and Roos, D. (1990) The Machine That Changed the World. Harper Perennial, New York.

[2] Fullerton, R.R., Kennedy, F.A. and Widener, S.K. (2014) Lean Manufacturing and Firm Performance: The Incremental Contribution of Lean Management Accounting Practices. Journal of Operations Management, 32, 414-428. https://doi.org/10.1016/j.jom.2014.09.002

[3] Jayaraman, K. and Teo, K.L. (2010) A Conceptual Framework for Critical Success Factors of Lean Six Sigma: Implementation on the Performance of Electronic Manufacturing Service Industry. International Journal of Lean Six Sigma, 1, 191-215. https://doi.org/10.1108/20401461011075008

[4] Hofer, C., Eroglu, C. and Hofer, A.R. (2012) The Effect of Lean Production on Financial Performance: The Mediating Role of Inventory Leanness. International Journal of Production Economics, 138, 242-253. https://doi.org/10.1016/j.ijpe.2012.03.025

[5] Angelopoulos, M. and Pollalis, Y. (2019) Critical Success Factors of Lean Management in Public Sector: Evidence from Greece. International Journal of Management and Applied Science, 5, 12-18.

[6] Vazakidis, A., Karagiannis, I. and Tsialta, A. (2010) Activity-Based Costing in the Public Sector. Journal of Social Sciences, 6, 376-382.

https://doi.org/10.3844/jssp.2010.376.382

[7] Angelopoulos, M. and Pollalis, Y. (2017) Using ABC Costing Method with in a KPI-Based Framework to a Lean Transformation of a Greek Public Company. MPRA Paper No. 79483, Munich Personal RePEc Archive, Germany. 
[8] Angelopoulos, M. and Pollalis, Y. (2019) Use of Open Data as a Tool for Successful Lean Management in Public Services: Evidence from Greece. SPOUDAI Journal of Economics and Business, 70, 117-127.

[9] Arlbjørn, S.J., Freytag, P.V. and de Haas, H. (2011) Service Supply Chain Management: A Survey of Lean Application in the Municipal Sector. International Journal of Physical Distribution and Logistics Management, 41, 277-295. https://doi.org/10.1108/09600031111123796

[10] de Almeida, J.P.L., Galina, S.V.R., Grande, M.M. and Brum, D.G. (2017) Lean Thinking: Planning and Implementation in the Public Sector. International Journal of Lean Six Sigma, 8, 390-410. https://doi.org/10.1108/IJLSS-06-2016-0027

[11] Dezdar, S. and Ainin, S. (2011) The Influence of Organizational Factors on Successful ERP Implementation. Management Decision, 49, 911-926. https://doi.org/10.1108/00251741111143603

[12] Somers, T.M. and Nelson, K.G. (2004) A Taxonomy of Players and Activities across the ERP Project Life Cycle. Information and Management, 41, 257-278. https://doi.org/10.1016/S0378-7206(03)00023-5

[13] Zhang, Z., Lee, M.K., Huang, P., Zhang, L. and Huang, X. (2005) A Framework of ERP Systems Implementation Success in China: An Empirical Study. International Journal of Production Economics, 98, 56-80. https://doi.org/10.1016/j.ijpe.2004.09.004

[14] Al-Mashari, M., Al-Mudimigh, A. and Zairi, M. (2003) Enterprise Resource Planning: A Taxonomy of Critical Factors. European Journal of Operational Research, 146, 352-364. https://doi.org/10.1016/S0377-2217(02)00554-4

[15] Hwang, D. and Min, H. (2015) Identifying the Drivers of Enterprise Resource Planning and Assessing Its Impacts on Supply Chain Performances. Industrial Management and Data Systems, 115, 541-569. https://doi.org/10.1108/IMDS-10-2014-0284

[16] Botta-Genoulaz, V., Millet, P.A. and Grabot, B. (2005) A Survey on the Recent Research Literature on ERP Systems. Computers in Industry, 56, 510-522.

https://doi.org/10.1016/j.compind.2005.02.004

[17] Ince, H., Imamoglu, S.Z., Keskin, H., Akgun, A. and Efe, M.N. (2013) The Impact of ERP Systems and Supply Chain Management Practices on Firm Performance: Case of Turkish Companies. Procedia-Social and Behavioral Sciences, 99, 1124-1133. https://doi.org/10.1016/j.sbspro.2013.10.586

[18] Kallunki, J.P., Laitinen, E.K. and Silvola, H. (2011) Impact of Enterprise Resource Planning Systems on Management Control Systems and Firm Performance. International Journal of Accounting Information Systems, 12, 20-39.

https://doi.org/10.1016/j.accinf.2010.02.001

[19] Ram, J., Corkindale, D. and Wu, M.L. (2013) Implementation Critical Success Factors (CSFs) for ERP: Do They Contribute to Implementation Success and Post-Implementation Performance? International Journal of Production Economics, 144, 157-174. https://doi.org/10.1016/j.ijpe.2013.01.032

[20] Taylor, G.R. (2005) Integrating Quantitative and Qualitative Methods in Research. University Press of America, Lanham.

[21] Saunders, M.N., Lewis, P. and Thornhill, A. (2009) Research Methods for Business Students. Pearson Education, London.

[22] Etikan, I., Musa, S.A. and Alkassim, R.S. (2016) Comparison of Convenience Sampling and Purposive Sampling. American Journal of Theoretical and Applied Statis- 
tics, 5, 1-4. https://doi.org/10.11648/j.ajtas.20160501.11

[23] Hauke, J. and Kossowski, T. (2011) Comparison of Values of Pearson's and Spearman's Correlation Coefficients on the Same Sets of Data. Quaestiones Geographicae, 30, 87-93. https://doi.org/10.2478/v10117-011-0021-1 